\title{
Erratum to: Design and implementation of a social networking platform for cloud deployment specialists
}

Kostas Magoutis ${ }^{1,2^{*}}$, Christos Papoulas ${ }^{1,3}$, Antonis Papaioannou ${ }^{1,3}$, Flora Karniavoura ${ }^{1,3}$,

Dimitrios-Georgios Akestoridis², Nikos Parotsidis², Maria Korozi ${ }^{1,3}$, Asterios Leonidis ${ }^{1,3}$, Stavroula Ntoa ${ }^{1}$

and Constantine Stephanidis ${ }^{1,3}$

It has come to the publisher's attention that the original PDF version of this article [1] unfortunately published many figures in the incorrect order. The order of the figures has been updated in the original PDF and is given for reference below.

\footnotetext{
*Correspondence: magoutis@ics.forth.gr

'Institute of Computer Science (ICS), Foundation for Research and

Technology - Hellas (FORTH), Heraklion, Greece

${ }^{2}$ Department of Computer Science and Engineering, University of loannina,

loannina, Greece

Full list of author information is available at the end of the article
} 


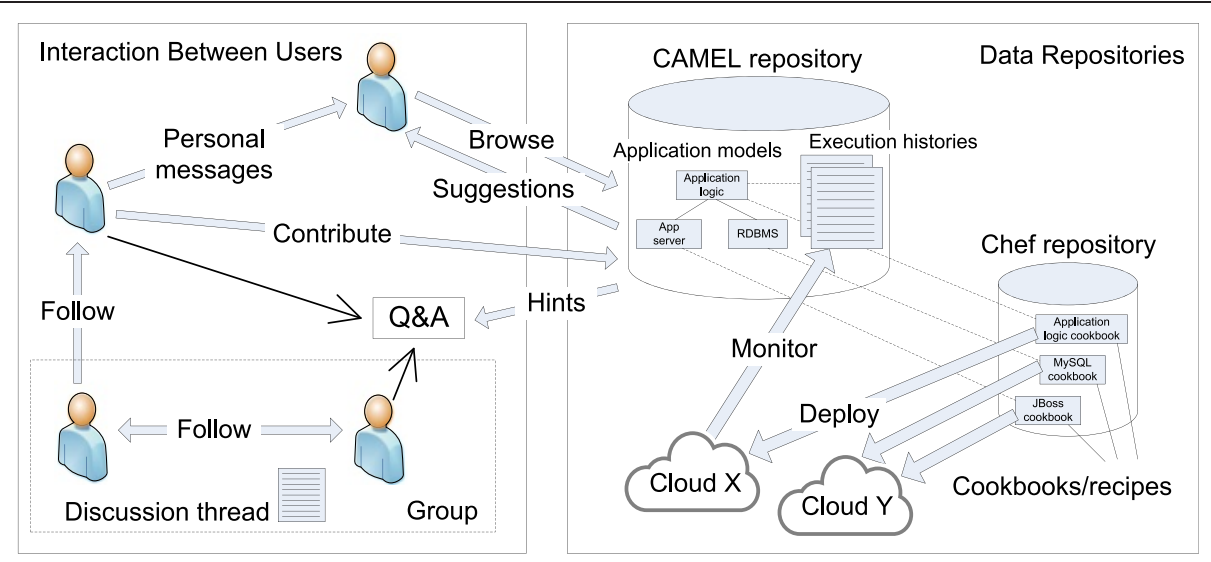

Fig. 1 Integration of a collaborative social platform with repositories of information

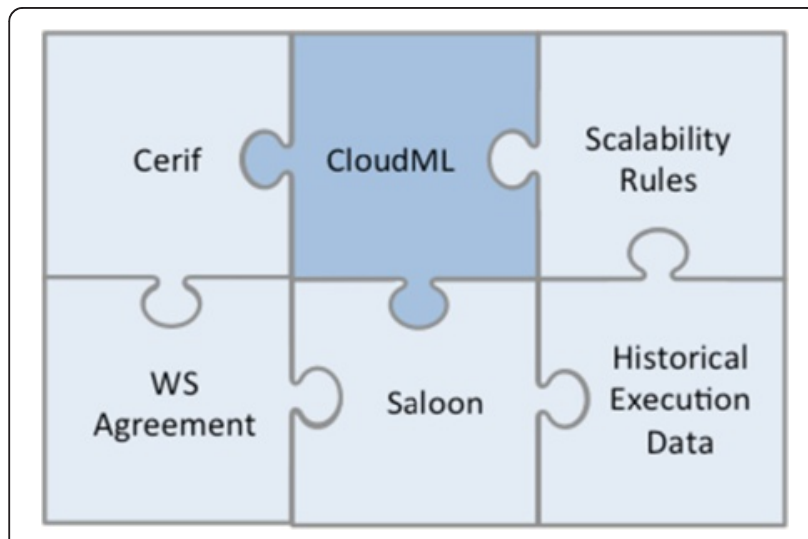

Fig. 2 DSLS comprising CAMEL 


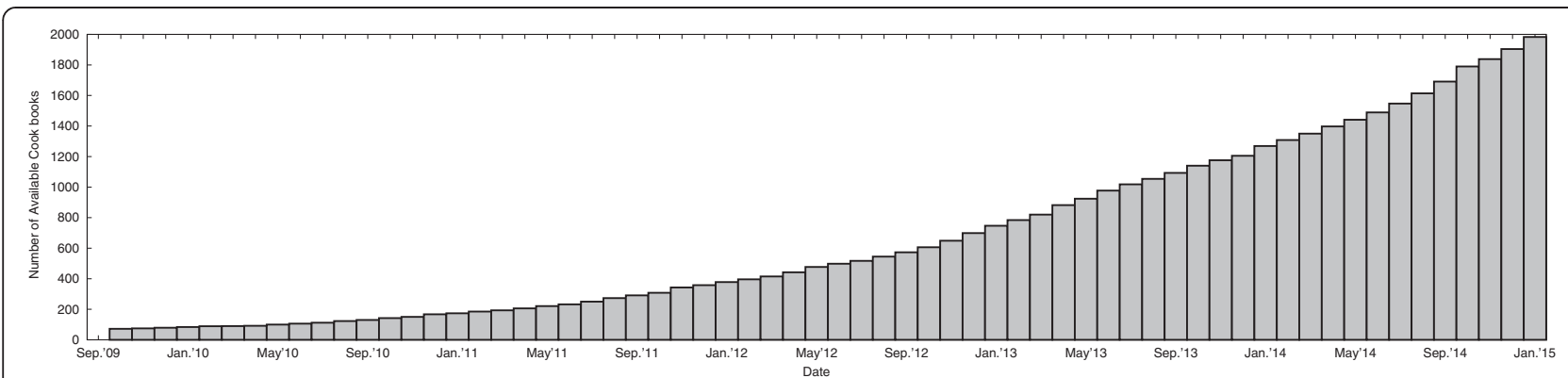

Fig. 3 Evolution of total number of cookbooks on Chef Supermarket over time

\begin{tabular}{|c|c|}
\hline Application Models & Application Components \\
\hline Explore & Explore \\
\hline View details & View details \\
\hline View executions & Use - Clone \\
\hline $\begin{array}{l}\text { Use - Deploy - Clone } \\
\text { Create new }\end{array}$ & Create new \\
\hline \multicolumn{2}{|c|}{ Comment / Rate / Share / Watch } \\
\hline \multicolumn{2}{|c|}{ Write Review } \\
\hline \multicolumn{2}{|c|}{ View top rated } \\
\hline \multicolumn{2}{|c|}{ View suggestions } \\
\hline
\end{tabular}

\section{Community}

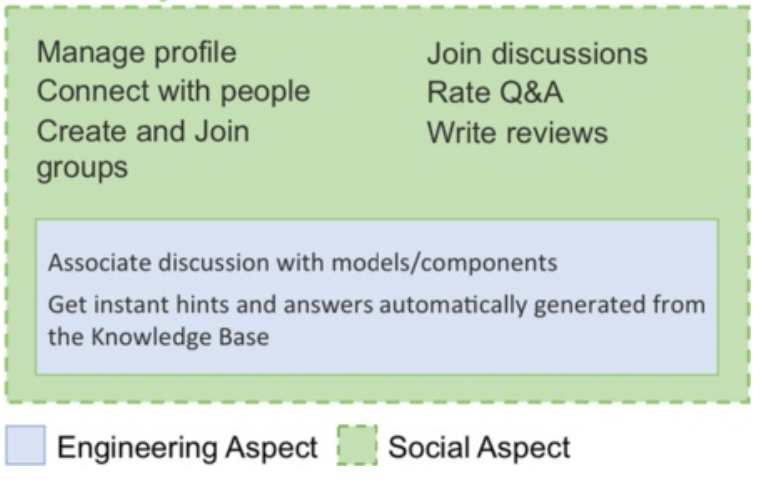

Fig. 4 Engineering and social activities are seamlessly interweaved within the PaaSage professional network 


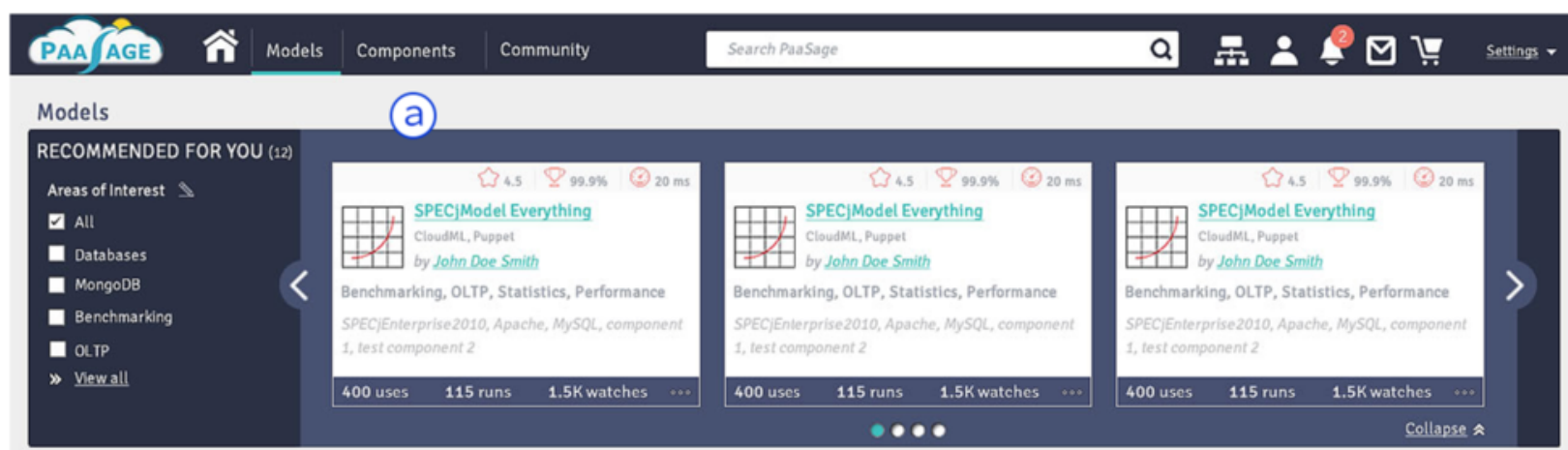

All Featured Top Newand Noteworthy

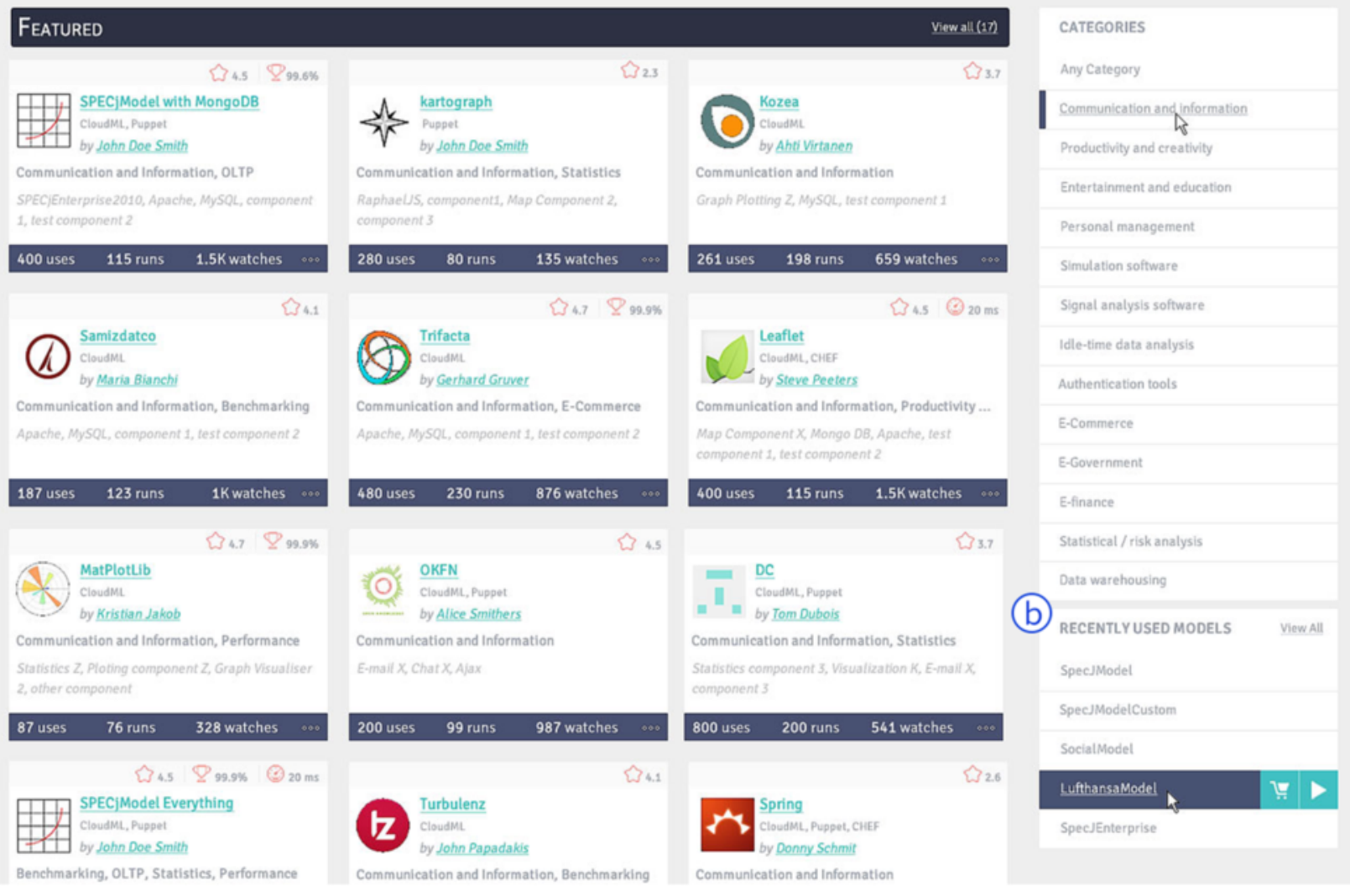

Fig. 5 Personalized models page 


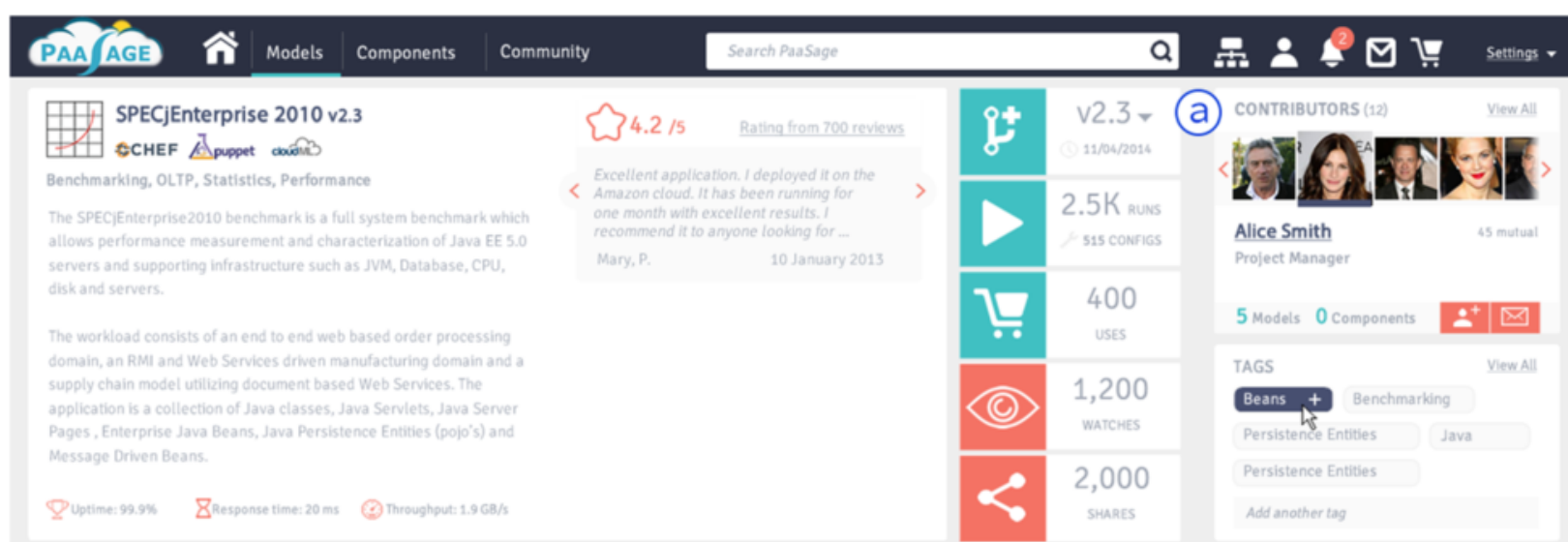

\section{RUNS COMPONENTS DISCUSSIONS REVIEWS SIMILARMODELS (b)}

\section{FILTERS}
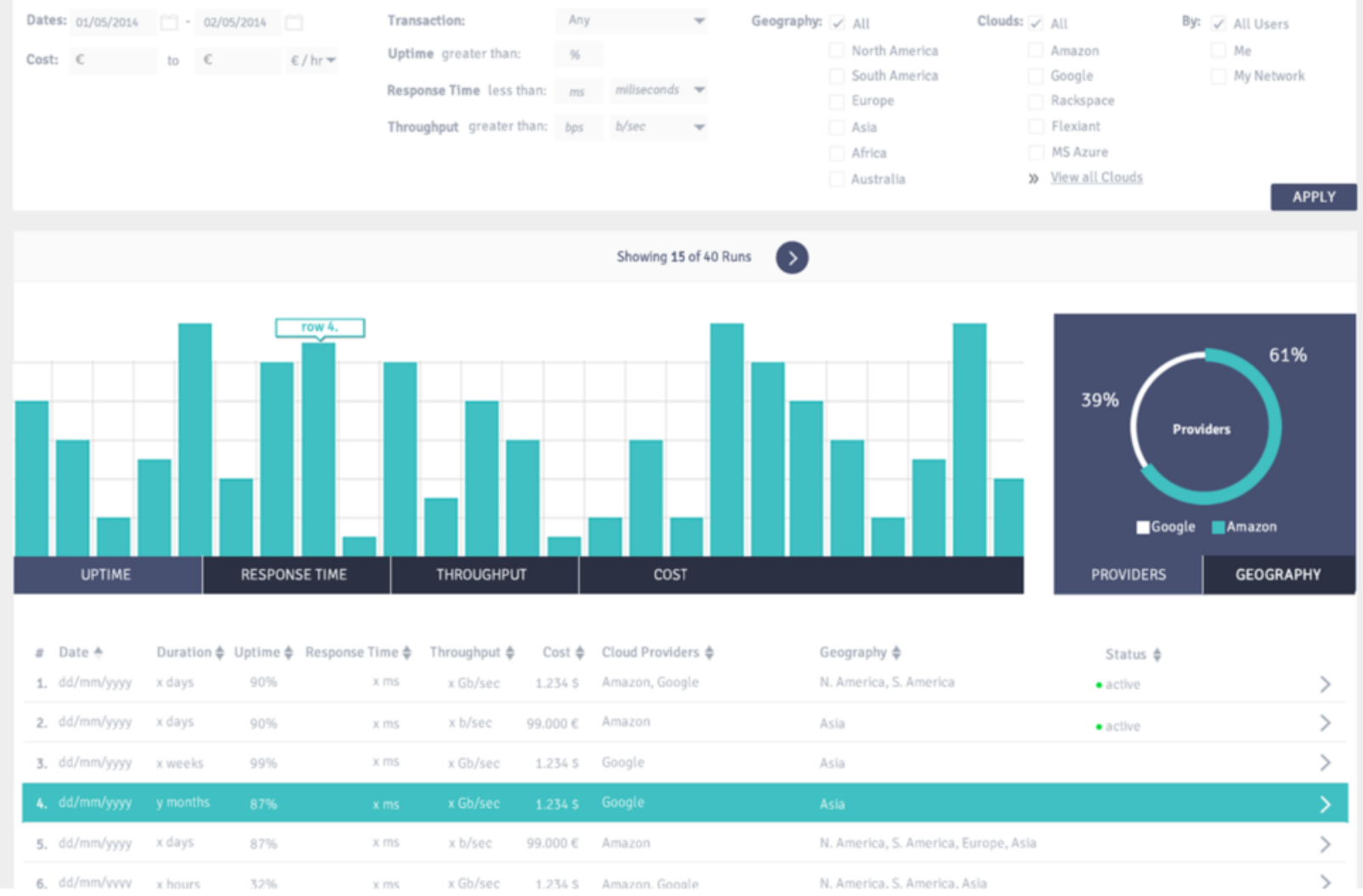

Fig. 6 Application model page 


\begin{tabular}{|c|c|}
\hline \multicolumn{2}{|c|}{ MODELS \& COMPONENTS LIST } \\
\hline 표 BenchmarkingModel & CloudML \\
\hline A WeatherComponent & Puppet \\
\hline 료 SpecjModel & ! chef \\
\hline \multicolumn{2}{|c|}{ Weather Components (12) } \\
\hline ․ㅗ. Spec|Model2010 & CloudML \\
\hline Ût Empty Cart & \\
\hline
\end{tabular}

Fig. 7 Models and components list

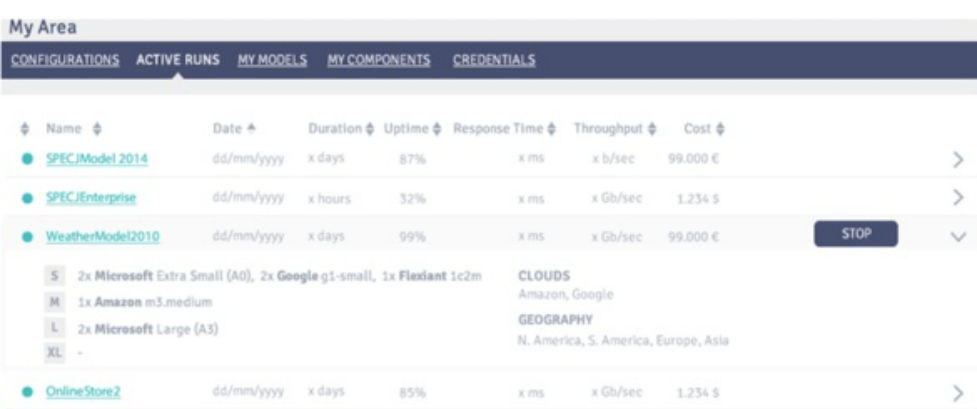

Fig. 8 List of currently running applications

$\begin{array}{ll}\text { SUGGESTED MEM BERS (12) } & \text { View All } \\ \text { SIMILAR GROUPS (12) }\end{array}$

Fig. 9 Users are constantly motivated to participate in social activities 


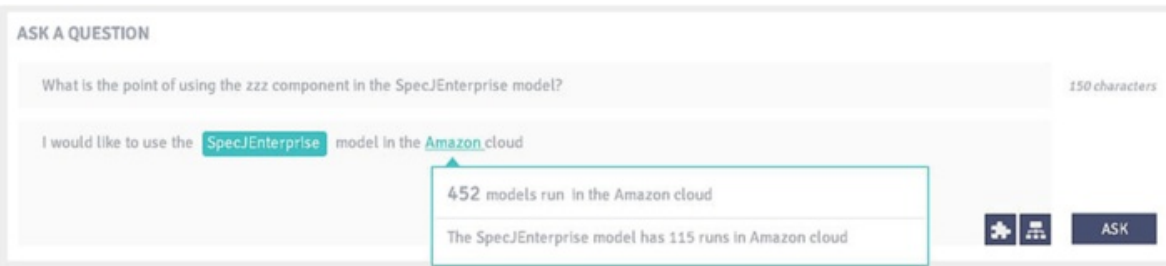

Fig. 10 Automatic provision of context-sensitive assistance when available

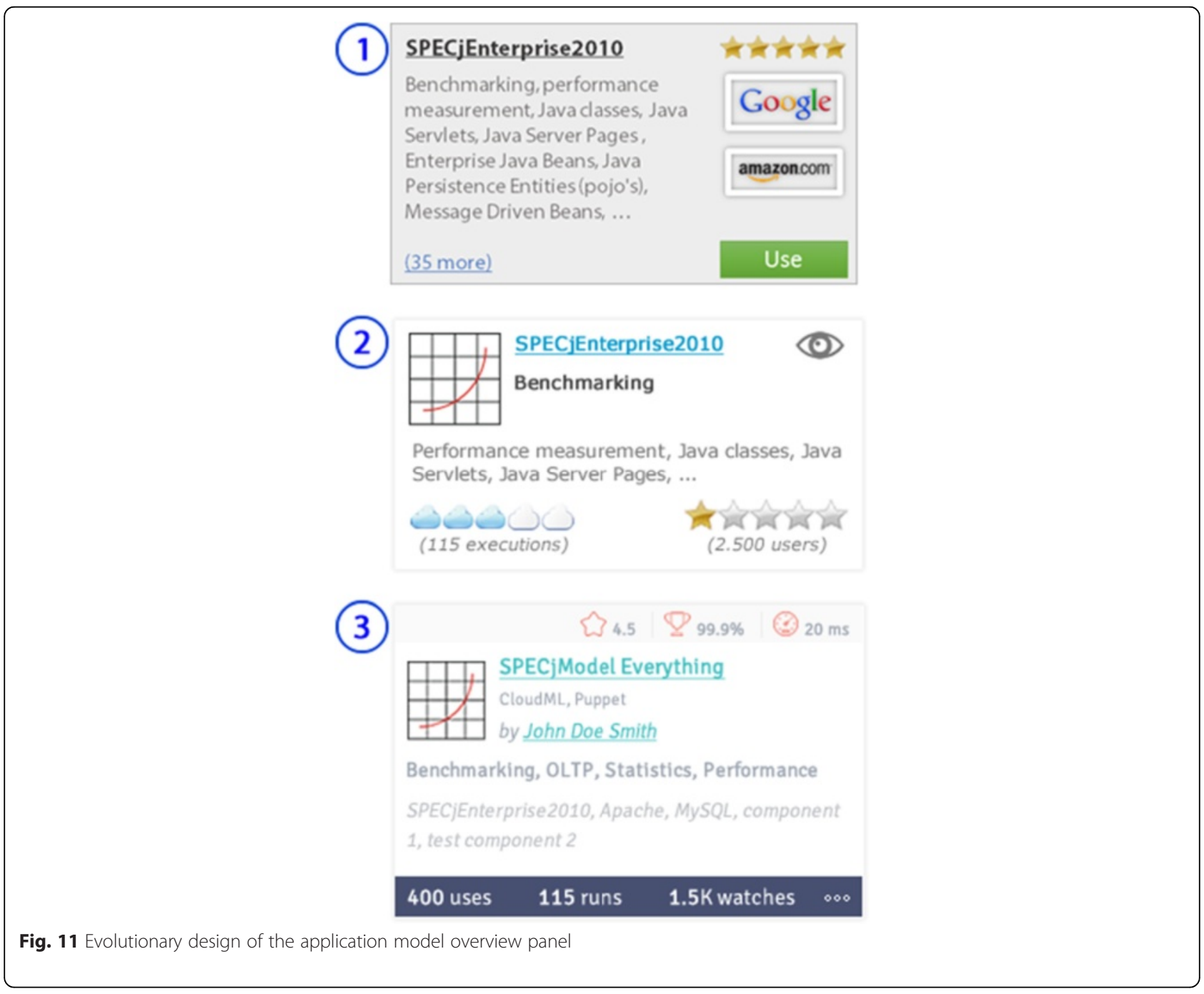

\section{PAA AGE $\widehat{A}$ Models Components Community \\ Search Paasage

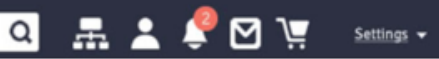 \\ (i) Homepage \& navigation to the network's content \\ (ii) Search \\ (iii) User's personal stuff}

Fig. 12 Main navigation menu 


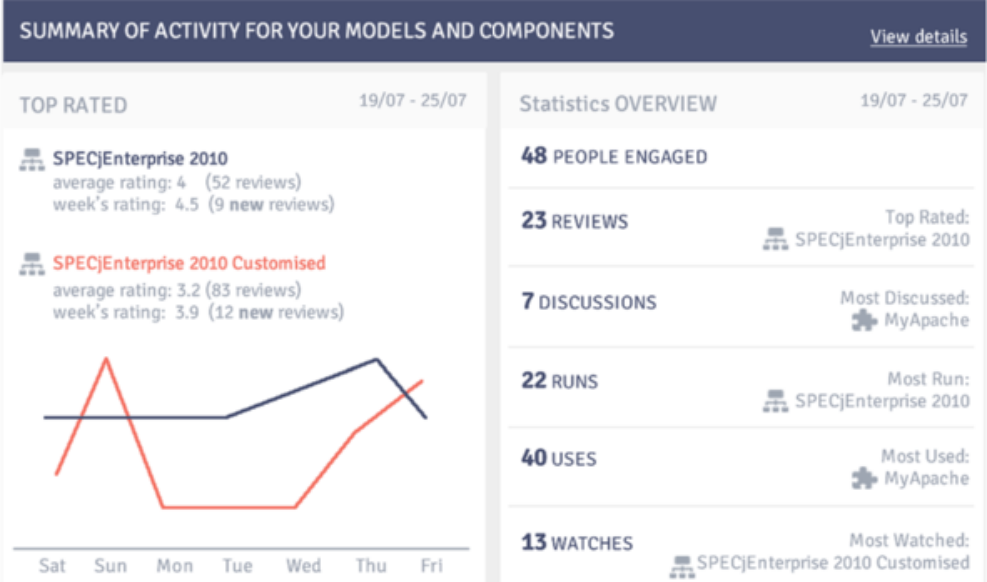

Fig. 13 Statistical information and graphics for user's models and components

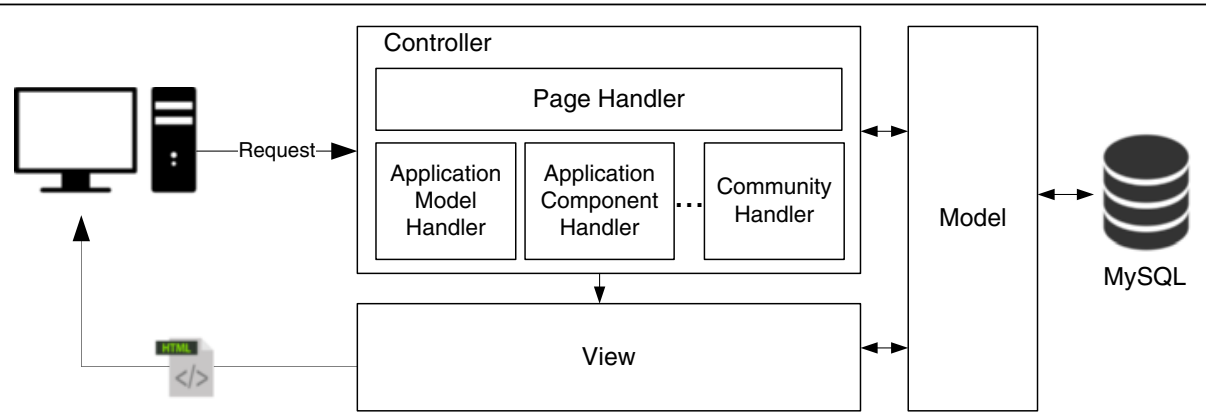

Fig. 14 Architecture of the Elgg Social Networking engine. Page handlers refer to functionality of implemented plugins

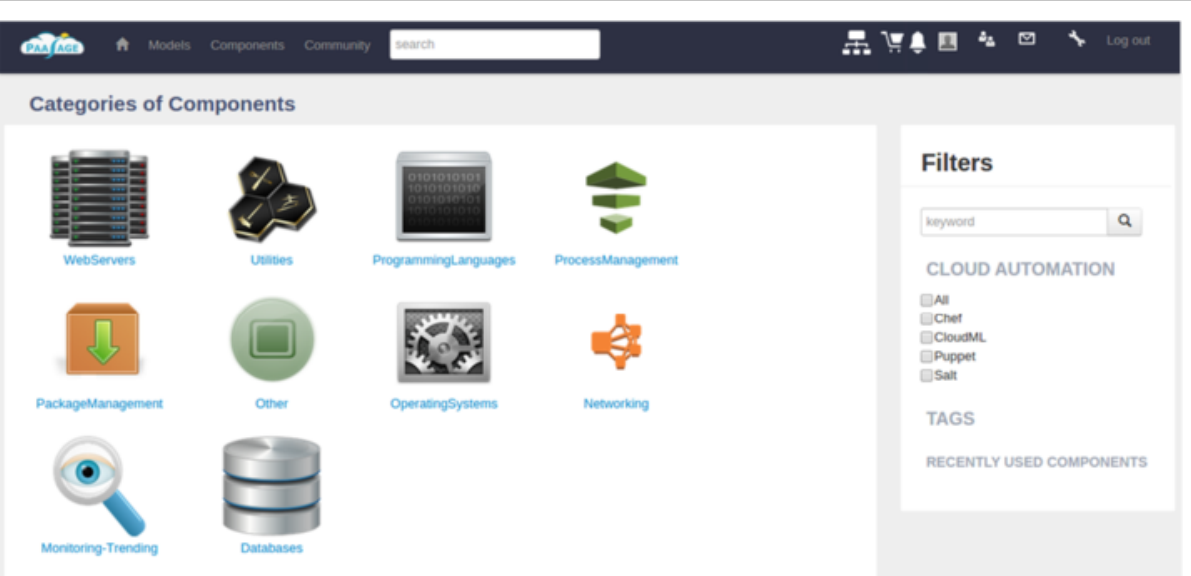

Fig. 15 Application components. Component categories and components imported from Chef Supermarket 


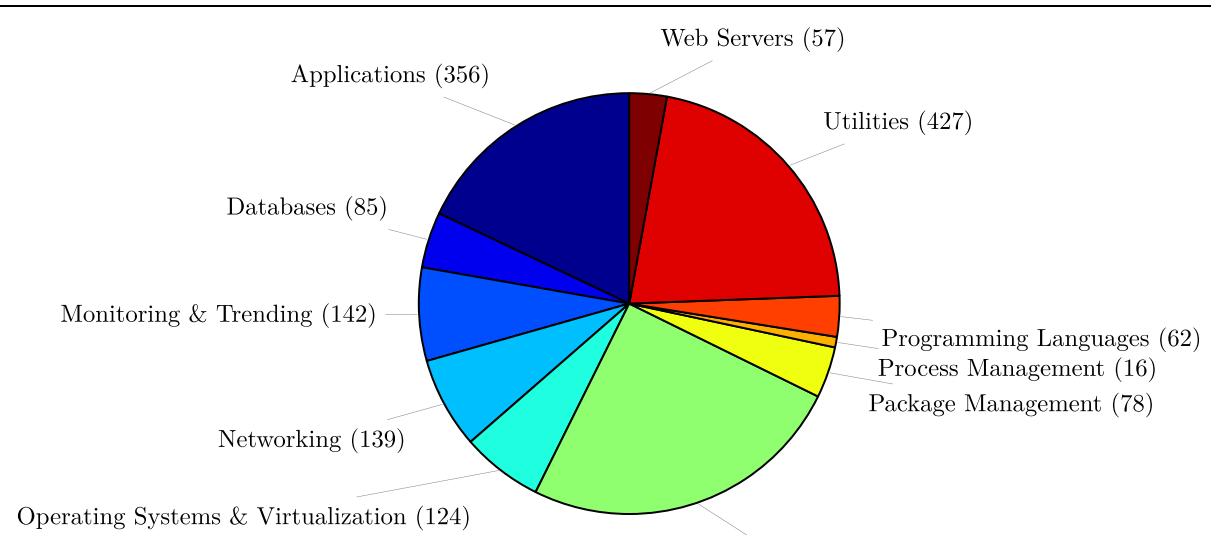

Other (497)

Fig. 16 Distribution of Chef cookbook categories

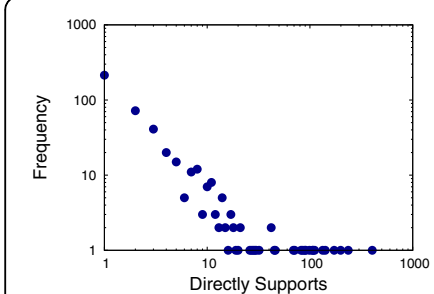

Fig. 17 Distribution of Chef cookbook dependencies in log-log scale
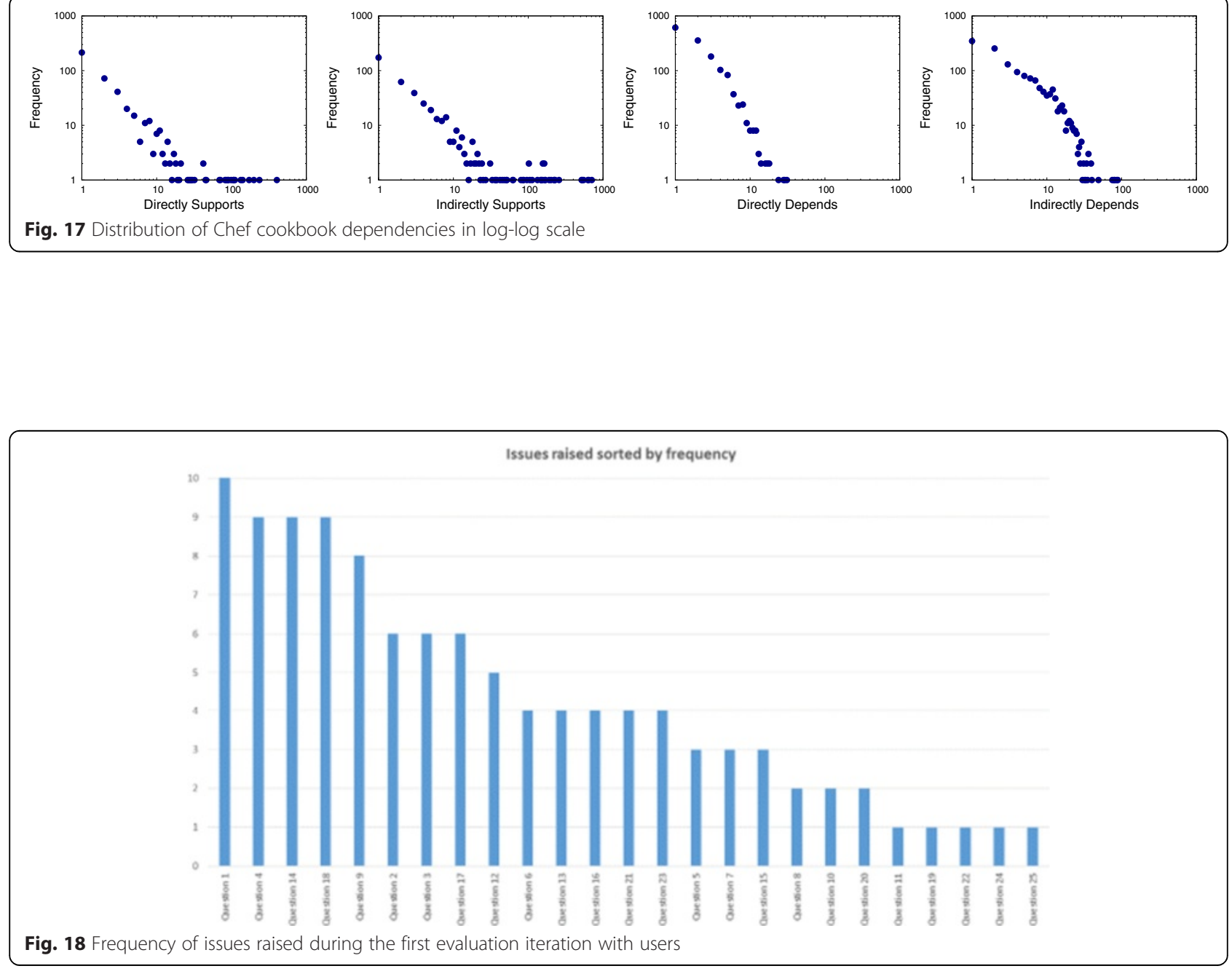


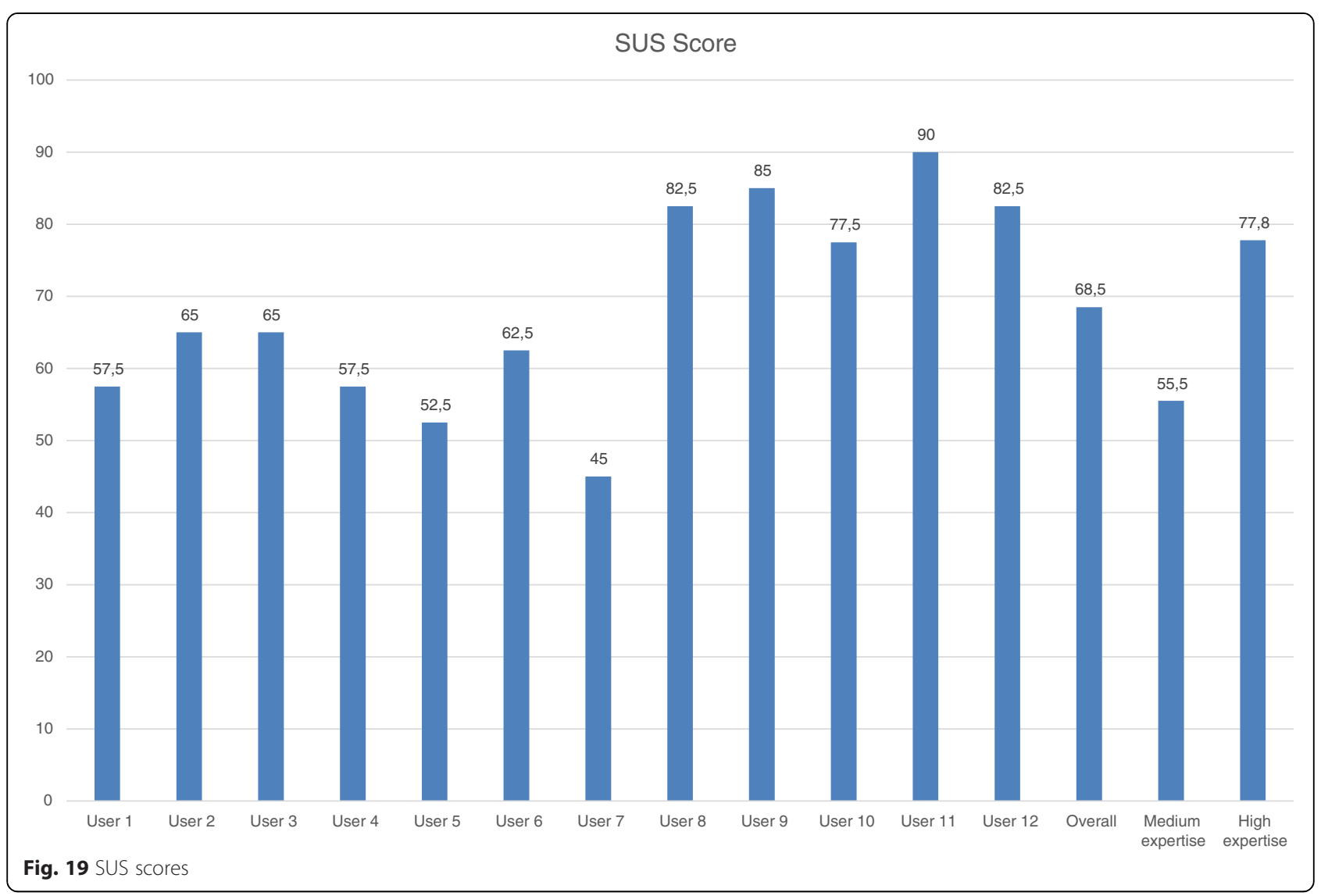



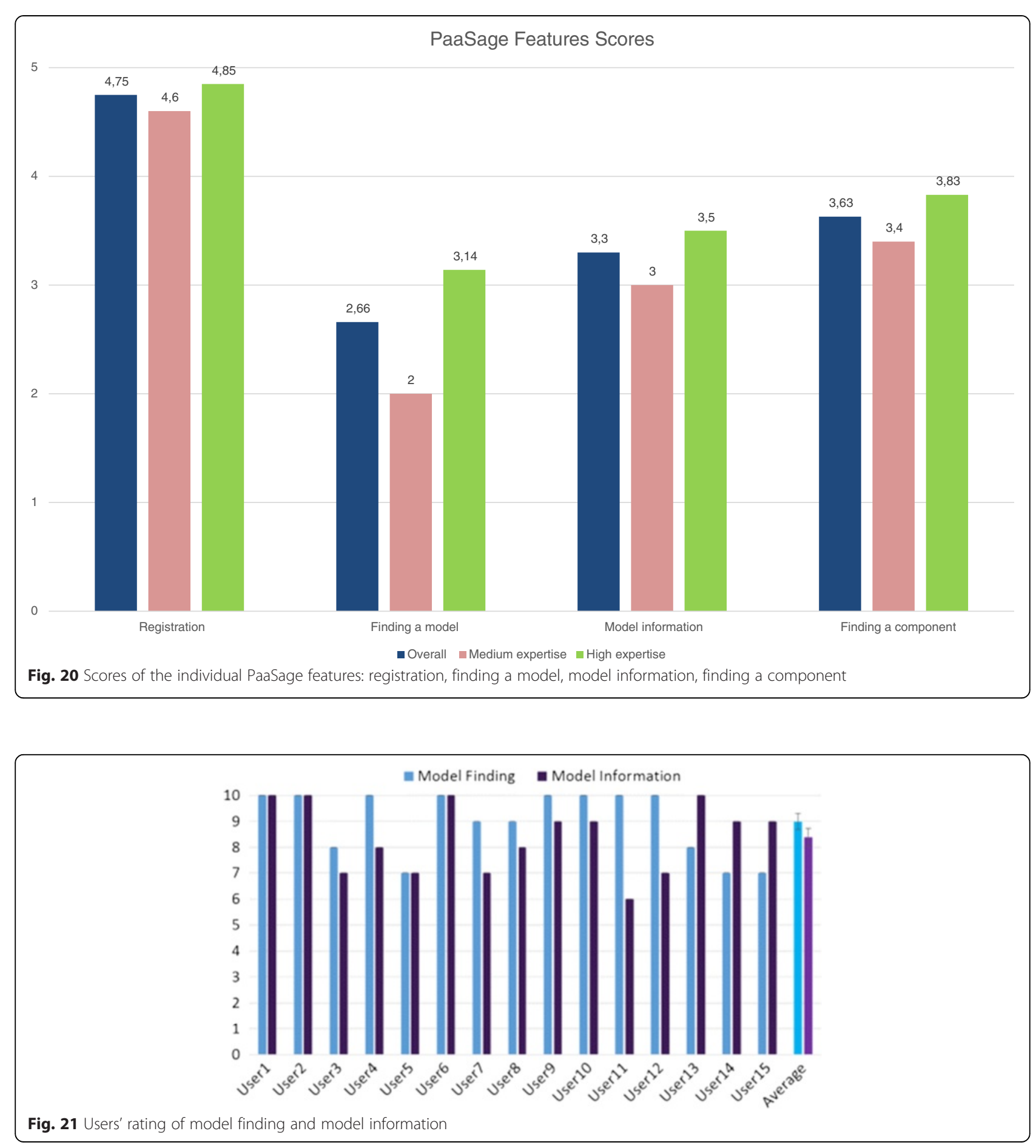

\section{View and share source code \\ Deployment scripts and instructions \\ Direct model execution \\ Application binaries \\ Software project management}

Fig. 22 User requests for DevOps features to be included in the PaaSage social network 


\section{Detailed model information \\ Automated replies \\ Model sharing \\ User profile tags UI design \\ Execution histories \\ Social features \\ Charts and statistical information \\ Projects and users connection}

Fig. 23 PaaSage features that were mostly liked by the users

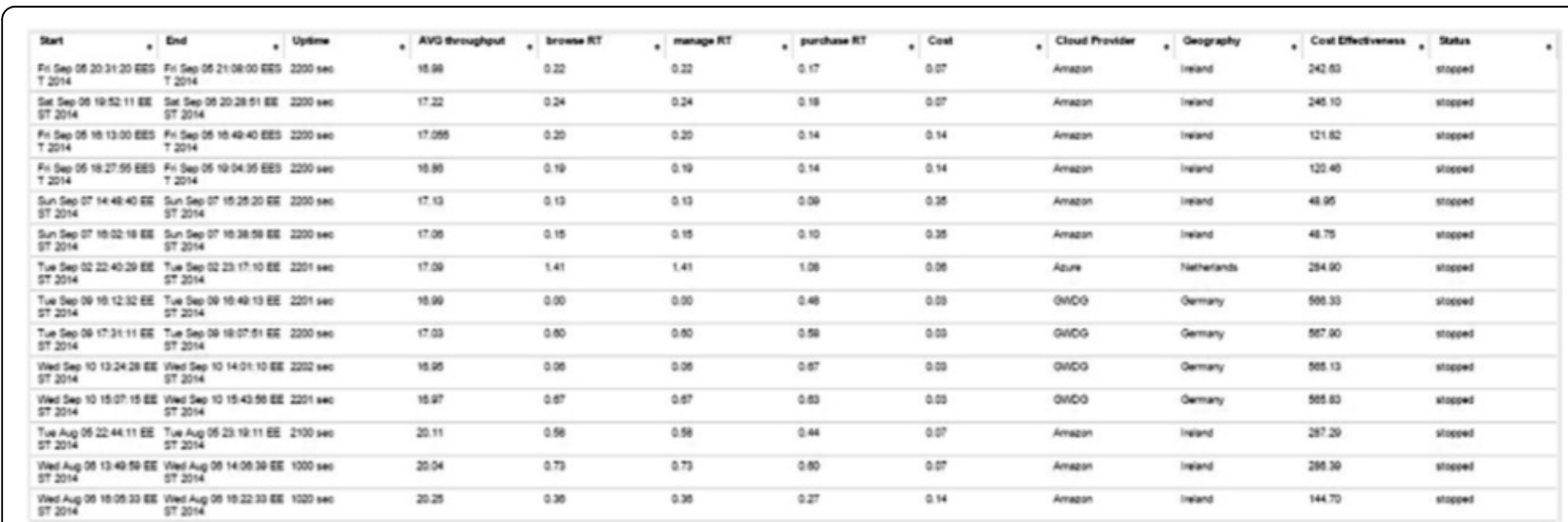

Fig. 24 The execution history of different cloud deployments

\section{Author details}

'Institute of Computer Science (ICS), Foundation for Research and

Technology - Hellas (FORTH), Heraklion, Greece. ${ }^{2}$ Department of Computer

Science and Engineering, University of loannina, loannina, Greece.

${ }^{3}$ Computer Science Department, University of Crete, Rethymnon, Greece.

\section{Published online: 13 October 2015}

\section{Reference}

1. Magoutis K, Papoulas C, Papaioannou A, Karniavoura F, Akestoridis D-G,

Parotsidis $\mathrm{N}$, et al. Design and implementation of a social networking

platform for cloud deployment specialists. J Internet Serv Appl. 2015; 6:19.

http://www.jisajournal.com/content/6/1/19. 